Непосредственно после проведенного курса лечения в 1 группе произошло улучшение остроты зрения, через месяц - у 5 пациентов (10 глаз) отмечено уменьшение количества геморрагий и микроаневризм. Через 3-6 месяцев положительная динамика у 5 пациентов (10 глаз) сохранилась, отмечено улучшение еще у 2 пациентов (4 глаза). Положительная динамика по допплерографии отмечена у 5 пациентов (10 глаз) через 1 месяц, и сохранялась в течение 6 месяцев.

В контрольной группе в периоды осмотра улучшений в картине глазного дна не отмечено, через 6 месяцев у 15 пациентов количество геморрагий увеличилось. Острота зрения у остальных пациентов оставалась неизменной.

Вывод: Данные обследования показывают выраженность ретинопротекторного действия ретиналамина, его продолжительное воздействие, на фоне компенсации состояния по основному заболеванию. Отмечено улучшение картины глазного дна, сохраняющейся длительный период времени - в течение 6 месяцев. Побочных реакций организма на данный препарат у больных выявлено не было.

\title{
***
}

1. Астахов Ю.С., Лисочкина А.В., Шадричев Ф.Е. Современные направления медикаментозного лечения непролиферативной диабетической ретинопа-тии // Клиническая офтальмология. - 2003. - Т. 4. - № 3. - С. 96-101.

2. Гаврилова Н.А. Патогенетические механизмы развития диабетической ре-тинопатии, диагностика ранних стадий, прогноз и профилактика развития, дифференцированный подход к лечению: Дис. доктора мед. наук. - М., 2004.

3. Дедов И.И. Диабетическая ретинопатия: современные проблемы // Сахарный диабет. - 2008. - № 3.1. - С. 48.

\section{Плащевой В.В. \\ Изучение эффективности препарата группы натрия кромогликат при лечении аллергических конъюнктивитов}

\author{
ЛДЦ «Анкор» \\ (Россия, Благовещенск)
}

doi: 10.18411/trnio-12-2021-323

\section{Аннотация}

В статье рассмотрены вопросы тактики лечения аллергических конъюнктивитов. Проведенные исследования доказали эффективность препарата группы натрия кромогликат при лечении аллергических конъюнктивитов. Данный препарат позволяет снизить жалобы пациентов и достичь высокого терапевтического результата. Побочных реакций у пациентов не наблюдалось.

Ключевые слова: натрия кромогликат, аллергический конъюнктивит, гиперемия конъюнктивы, аллергический отёк, аллергическая реакция.

\section{Abstract}

The article discusses the issues of tactics of treatment of allergic conjunctivitis. The conducted studies have proved the effectiveness of the sodium kromoglycat group drug in the treatment of allergic conjunctivitis. This drug allows you to reduce patient complaints and achieve a high therapeutic result. No adverse reactions were observed in patients.

Keywords: sodium cromoglycate, allergic conjunctivitis, conjunctival hyperemia, allergic edema, allergic reaction.

\section{Введение}

Аллергические заболевания охватывают в среднем около 15 \% населения земного шара. В регионах с аллергической заболеваемостью повышенная чувствительность к 
аллергенам является одним из основных факторов, ограничивающих активность людей трудоспособного возраста. Главными целями терапии являются определение основных причин аллергизации, предотвращение обострений заболевания, поддержание нормальной активности пациента, предотвращение развития тяжелых форм заболевания, лечение сопутствующих заболеваний и повышение качества жизни [1].

К основным препаратам, применяющимся при лечении аллергических конъюнктивитов, относятся:

1) стабилизаторы мембран тучных клеток;

2) блокаторы Н1-гистаминовых рецепторов;

3) отдельные комбинации блокаторов гистаминовых рецепторов и стабилизаторы тучных клеток, которые обеспечивают быстрый эффект, но противопоказаны пациентам с закрытоугольной глаукомой;

4) кортикостероиды, снимающие общие симптомы воспаления и аллергии, но повышающие риск образования задних субкапсулярных катаракт, присоединения вторичной инфекции, повышения внутриглазного давления (ВГД), замедляющие заживление ран;

5) нестероидные противовоспалительные средства (НПВС), ограничивающие экссудативные проявления воспаления [2].

Из-за необходимости длительного курсового применения, большое значение приобретает наличие противоаллергических препаратов для пациентов. Поэтому одной из тенденций современной фармакотерапии аллергопатологии является все более распространенное использование отечественных препаратов, что обусловлено главным образом их более низкой стоимостью.

\section{Цель исследования.}

Цель исследования - изучить эффективность препарата группы натрия кромогликат при лечении аллергических конъюнктивитов.

\section{Материалы и методы.}

Под наблюдением находилось 50 пациентов (100 глаз) в возрасте от 25 до 70 лет. Большую часть пациентов составляли женщины - 31 человек, мужчин - 19 человек. Всех пациентов с аллергическими конъюнктивитами разделены на две однородные по клиническим проявлениям группы в зависимости от проводимой терапии:

- 1-я группа - 25 пациентов (50 глаз) - основная группа. На фоне базисного лечения закапывали препарат группы натрия кромогликат: по 2 капли 4 раза в день. Курс лечения составлял 4 недели.

- 2-я группа - 25 пациентов (50 глаз) - контрольная группа. На фоне лечения закапывали зарубежный препарат группы натрия кромогликат: по 2 капли 4 раза в день. Курс лечения составлял 4 недели.

Офтальмологическое обследование включало: визометрия, биомикроскопия, осмотр при фокальном освещении. Проводились аллергические тесты на специфические аллергены в период ремиссии заболевания.

\section{Результаты исследования.}

До начала исследования основной жалобой пациентов в основной и контрольной группах было:

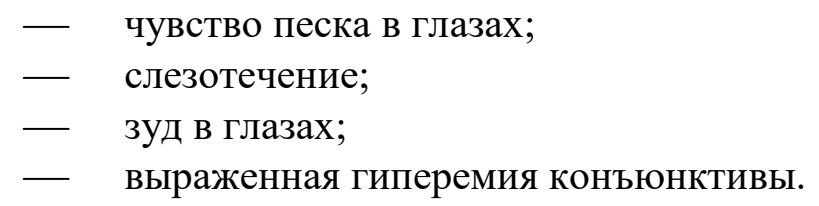

Спустя 2 недели лечения у пациентов основной группы с аллергическим отеком конъюнктивы век клинические проявления снизились и сохранялись лишь в 19 \% случаев, которые к концу лечения были купированы. 
Аллергическая реакция, наблюдающаяся у 5 пациентов контрольной группы, к концу второй недели сохраняется в 11 \% случаев, к концу лечения признаки аллергической реакции были купированы. У пациентов контрольной группы гиперемия конъюнктивы век к концу второй недели сохранялась в 58,9 \% - (8 глаз) случаев, к концу лечения отмечалась лишь в 10 \% случаев.

В основной группе пациентов с фолликулярным конъюнктивитом ко 2-й неделе лечения единичные фолликулы наблюдались в 25 \% случаев, и к концу проводимого курса лечения они рассосались. Множественные фолликулы, наблюдаемые у 4 пациентов, к концу второй недели лечения сохранялись в 35 \% случаев, к концу 4-й недели - в 15 \% случаев. В контрольной группе пациентов единичные фолликулы, выявленные у 2 пациентов, к концу 2-й недели лечения отмечались в 15 \% случаев, после 4-недельной терапии наблюдалось полное рассасывание фолликулов.

У пациентов обеих групп к концу курса лечения отмечался сопоставимый терапевтический эффект: значительная положительная динамика и купирование симптомов аллергического воспаления, эффективность лечения составила $96 \%$ в основной и контрольной группах.

\section{Вывод.}

Проведенные исследования доказали эффективность применения отечественного препарата группы натрия кромогликат. Данный препарат позволяет снизить жалобы пациентов и достичь высокого терапевтического результата. Побочных реакций у пациентов не наблюдалось. Проведенные исследования подтверждают значимость и необходимость применения отечественного препарата группы натрия кромогликата.

$$
* * *
$$

1. Нероев В.В., Вахова Е.С. Аллергические конъюнктивиты. Офтальмология: Национальное руководство. В кн.: Аветисов С.Э., Егоров Е.А., Мошетова Л.К. и др., ред. 2-е изд. Москва: ГЭОТАР-Медиа; 2018: 442-56.

2. Бржеский В.В. Аллергический конъюнктивит: путеводитель для офтальмолога амбулаторного звена. Медицинское обозрение. 2018; 1 (2): 74-9.

3. Егоров А.Е., Захарова М.А. Лечение пациента с аллергическим конъюнктивитом: рекомендации офтальмологу амбулаторного звена. Офтальмология. 2017; 2: 111 - 4.

4. Майчук Д.Ю, Куренков В.В., Кашникова О.А. // Актуальные вопросы воспалительных заболеваний глаз. М. $-2001 .-$ C. $232-234$.

\section{Рахимова С.С., Жолдыбай М.М., Перевезенцева В.М., Сакенова М.М. Гранулематоз с полиангиитом: трудности диагностики (случай с практики)}

$$
\text { НАО «Медиџинский университет Караганды»» }
$$

(Казахстан, Караганда)

doi: 10.18411/trnio-12-2021-324

\section{Аннотация}

Гранулематоз с полиангиитом - гранулематозное воспаление респираторного тракта и некротизирующий васкулит, поражающий мелкие и средние сосуды (капилляры, венулы, артериолы, артерии), обычно сочетающийся с некротизирующим гломерулонефритом. Диагностика заболевания весьма затруднительна. Из иммунологических исследований ключевая роль принадлежит определению антител к цитоплазме нейтрофилов. Золотым стандартом для подтверждения диагноза васкулита остается гистологическое исследование пораженной ткани.

Ключевые слова: гранулематоз с полиангиитом, антинейтрофильные цитоплазматические антитела. 